\title{
NR2F1 database: 111 variants and 83 patients support refining the clinical synopsis of Bosch-Boonstra-Schaaf optic atrophy syndrome
}

\author{
Benjamin Billiet ${ }^{1}$, Patrizia Amati-Bonneau ${ }^{2}$, Valérie Desquiret-Dumas ${ }^{2}$, Khadidja \\ Guehlouz $^{3}$, Dan Milea ${ }^{4}$, Philippe Gohier ${ }^{1}$, Guy Lenaers ${ }^{2}$, Delphine Mirebeau-Prunier ${ }^{2}$, \\ Johan Den Dunnen ${ }^{5}$, Pascal Reynier ${ }^{2}$, and Marc Ferré ${ }^{2}$ \\ ${ }^{1}$ Centre Hospitalier Universitaire d'Angers \\ ${ }^{2}$ Université d'Angers \\ ${ }^{3} \mathrm{CHU}$ Angers \\ ${ }^{4}$ Singapore National Eye Centre \\ ${ }^{5}$ Leiden University Medical Center
}

June 29, 2021

\begin{abstract}
Pathogenic variants of the nuclear receptor subfamily 2 group F member 1 gene (NR2F1) are responsible for Bosch-BoonstraSchaaf optic atrophy syndrome (BBSOAS), an autosomal dominant disorder characterized by optic atrophy associated with developmental delay and intellectual disability, but with a clinical presentation which appears to be multifaceted. We created the first public locus-specific database (LSDB) dedicated to NR2F1. All variants and clinical cases reported in the literature, as well as new unpublished cases, were integrated into the database using standard nomenclature to describe both molecular and phenotypic anomalies. We subsequently pursued a comprehensive approach based on computed representation and analysis suggesting a refinement of the BBSOAS clinical description with respect to neurological features and the inclusion of musculoskeletal hypotonia and intestinal signs with feeding difficulties. This database is fully accessible for both clinician and molecular biologists and should prove useful in further refining the clinical synopsis of NR2F1 as new data is recorded.
\end{abstract}

\section{Hosted file}

BILLIET-Manuscript.2021-06-06.docx available at https://authorea.com/users/422692/articles/ 528360-nr2f1-database-111-variants-and-83-patients-support-refining-the-clinicalsynopsis-of-bosch-boonstra-schaaf-optic-atrophy-syndrome 
figures/Figure-1/Figure-1-eps-converted-to.pdf 
figures/Figure-2/Figure-2-eps-converted-to.pdf 
figures/Figure-3/Figure-3-eps-converted-to.pdf 
figures/Figure-4/Figure-4-eps-converted-to.pdf

\section{Hosted file}

Table_1.docx available at https://authorea.com/users/422692/articles/528360-nr2f1-database111-variants-and-83-patients-support-refining-the-clinical-synopsis-of-bosch-boonstraschaaf-optic-atrophy-syndrome

\section{Hosted file}

Table_2.docx available at https://authorea.com/users/422692/articles/528360-nr2f1-database111-variants-and-83-patients-support-refining-the-clinical-synopsis-of-bosch-boonstraschaaf-optic-atrophy-syndrome 